\title{
Inhibition of polyadenylation reduces inflammatory gene induction
}

\author{
ALEXANDER KONDRASHOV ${ }^{1,3}$ HEDDA A. MEIJER, ${ }^{2,3,4}$ ADELINE BARTHET-BARATEIG, ${ }^{1}$ HANNAH N. PARKER, ${ }^{1}$ \\ ASMA KHURSHID, ${ }^{1}$ SARAH TESSIER, ${ }^{1}$ MARIE SICARD, ${ }^{1}$ ALAN J. KNOX, ${ }^{2}$ LINHUA PANG, ${ }^{2}$ \\ and CORNELIA H. DE MOOR ${ }^{1,5}$ \\ ${ }^{1}$ School of Pharmacy, The University of Nottingham, Nottingham, NG7 2RD, United Kingdom \\ ${ }^{2}$ School of Clinical Sciences, The University of Nottingham, Nottingham, NG7 2RD, United Kingdom
}

\begin{abstract}
Cordycepin ( $3^{\prime}$ deoxyadenosine) has long been used in the study of in vitro assembled polyadenylation complexes, because it terminates the poly(A) tail and arrests the cleavage complex. It is derived from caterpillar fungi, which are highly prized in Chinese traditional medicine. Here we show that cordycepin specifically inhibits the induction of inflammatory mRNAs by cytokines in human airway smooth muscle cells without affecting the expression of control mRNAs. Cordycepin treatment results in shorter poly $(A)$ tails, and a reduction in the efficiency of $m R N A$ cleavage and transcription termination is observed, indicating that the effects of cordycepin on $3^{\prime}$ processing in cells are similar to those described in in vitro reactions. For the CCL2 and CXCL1 mRNAs, the effects of cordycepin are post-transcriptional, with the mRNA disappearing during or immediately after nuclear export. In contrast, although the recruitment of RNA polymerase II to the IL8 promoter is also unaffected, the levels of nascent transcript are reduced, indicating a defect in transcription elongation. We show that a reporter construct with 3' sequences from a histone gene is unaffected by cordycepin, while CXCL1 sequences confer cordycepin sensitivity to the reporter, demonstrating that polyadenylation is indeed required for the effect of cordycepin on gene expression. In addition, treatment with another polyadenyation inhibitor and knockdown of poly $(\mathrm{A})$ polymerase $\alpha$ also specifically reduced the induction of inflammatory mRNAs. These data demonstrate that there are differences in the $3^{\prime}$ processing of inflammatory and housekeeping genes and identify polyadenylation as a novel target for anti-inflammatory drugs.
\end{abstract}

Keywords: polyadenylation; transcription termination; cordycepin; inflammation; anti-inflammatory drugs; poly(A) polymerase

\section{INTRODUCTION}

Inflammation is an important process that mediates the response of the body to infection and injury. Misregulated inflammation causes chronic inflammatory diseases such as asthma and rheumatoid arthritis and contributes to many other conditions including cancer, cardiovascular disease, and diabetes (Karin 2006; Barnes 2010; Hummasti and Hotamisligil 2010; Puntmann et al. 2010). Inflammatory cytokines mediate a well-defined inflammatory response in many cell types through transcription factor families such as NFKB, AP-1, STAT, and IRF. Central to NFкB-mediated transcription

\footnotetext{
${ }^{3}$ These authors contributed equally to this work.

${ }^{4}$ Present address: MRC Toxicology Unit, Leicester, LE1 9HN, United Kingdom

${ }^{5}$ Corresponding author

E-mail cornelia.demoor@nottingham.ac.uk

Article published online ahead of print. Article and publication date are at http://www.rnajournal.org/cgi/doi/10.1261/rna.032391.112.
}

is the degradation of cytoplasmic IкB, leading to the release and translocation of $\mathrm{NF} \kappa \mathrm{B}$ to the nucleus. This induces the transient transcription of inflammatory genes, including cytokines, chemokines, and PTGS2 (Beg and Baltimore 1996; Hoffmann et al. 2003; Tian et al. 2005). While the transcriptional induction determines which genes respond to inflammatory stimuli, the stability of the mRNAs produced by inflammatory genes determines the timing of the response (Hao and Baltimore 2009). Therefore, as in the most current understanding of gene expression, the major regulators of the levels of inflammatory mRNAs are thought to be localized in the promoter of the gene (for transcription) and the $3^{\prime}$-untranslated region of the mRNA (for mRNA stability).

An aspect of inflammatory gene expression that has received much less attention is the $3^{\prime}$ processing of these mRNAs. In general, all mRNAs are thought to be cleaved soon after the cleavage site has been transcribed and, with the exception of histone mRNAs, become polyadenylated immediately afterward (Zhang et al. 2010; Di Giammartino 
et al. 2011; Proudfoot 2011). Cleavage and polyadenylation factors are recruited to the RNA when the polyadenylation signal and surrounding sequences emerge from the RNA polymerase. The efficiency of this step is dependent on the sequence of the polyadenylation signal and other elements in its close vicinity (Moore and Proudfoot 2009; Richard and Manley 2009; Wang et al. 2010; Zhang et al. 2010). Cleavage of the mRNA is also required for efficient termination of transcription by RNA polymerase II (Luo et al. 2006; West et al. 2008; Richard and Manley 2009). Termination is influenced by the rate of transcription elongation, by the efficiency of cleavage and polyadenylation, as well as by sequences found in the terminator region and in the promoter, giving rise to gene-specific effects on termination rates (Banerjee et al. 2009; West and Proudfoot 2009; Milcarek et al. 2011; Mukundan and Ansari 2011). Recently, five research groups reported that the induction of specific mRNAs by transcription factors and their associated transacting factors are mediated to a significant extent by effects on cleavage, polyadenylation, and transcription termination (Chipumuro and Henriksen 2011; Milcarek et al. 2011; Mukundan and Ansari 2011; Nagaike et al. 2011; Waldholm et al. 2011). One of these studies describes STAT1-mediated recruitment of polyadenylation factors to the IRF1 gene through chromatin modification of the terminator region of this gene (Chipumuro and Henriksen 2011). These recent discoveries indicate that cleavage, polyadenylation, and transcription termination are commonly regulated in a gene-specific manner, and that they are likely to also play a role in the induction of inflammatory gene expression.

The polyadenylation inhibitor cordycepin ( $3^{\prime}$ deoxyadenosine) is an active component of the caterpillar fungi (Cordyceps or Ophiocordyceps). These fungi are highly prized in Tibetan and Chinese traditional medicine and used for a large number of afflictions, including kidney, heart, and lung conditions such as asthma (Winkler 2010). A variety of studies indicate that cordycepin has clear biological activities, it is antiproliferative, antimetastatic, and anti-inflammatory, and it inhibits the unfolded protein response (Nakamura et al. 2005; Lee et al. 2009, 2010; Noh et al. 2009; Wong et al. 2010; Cheng et al. 2011; Kim et al. 2011; Kitamura et al. 2011). Because of its structure, cordycepin could potentially interfere with any process requiring adenosine or ATP. In particular, cordycepin triphosphate was proposed to be a chain terminator for transcription, but it was reported early that total nuclear mRNA precursors are less affected than cytoplasmic mRNA (Penman et al. 1970). In contrast, it has been demonstrated to be an efficient chain terminator for mRNA polyadenylation by poly(A) polymerases (Rose et al. 1977). In addition, some studies indicate that cordycepin may act through adenosine receptors, by inhibiting poly(ADP) ribose polymerase (PARP) or by modulating methylation reactions through incorporation in an S-adenosylmethionine ana$\log$ (Kredich 1980; Chen et al. 2010; Kim et al. 2011).
In this study we show that cordycepin specifically inhibits the expression of inflammatory mRNAs and affects mRNA polyadenylation and cleavage in cells. Other methods of reducing polyadenylation also affect the inflammatory mRNAs. All of our data are consistent with cordycepin affecting inflammatory gene expression through its ability to inhibit polyadenylation, providing new avenues for the development of anti-inflammatory drugs.

\section{RESULTS}

\section{Cordycepin affects the nuclear polyadenylation of newly transcribed mRNAs}

We have previously demonstrated that cordycepin affects the poly(A) tails and the abundance of steady-state mRNAs in HeLa and NIH3T3 cells. We hypothesized that this was through inhibition of polyadenylation of newly made mRNAs (Wong et al. 2010). To determine whether cordycepin does indeed have effects on nuclear polyadenylation, we treated HeLa cells and NIH3T3 fibroblasts with cordycepin for $2 \mathrm{~h}$ and isolated nuclear and cytoplasmic RNA. To determine the length of poly(A) tails, we used 3 '-end labeling followed by degradation of the non-poly(A) RNA with RNAses A and $\mathrm{T} 1$ and electrophoresis on a denaturing polyacrylamide gel. As can be seen in Figure 1A, cordycepin affected the maximal poly(A) tail length in the cytoplasm only by $50-80$ residues, but had a much stronger effect on the nuclear poly(A) content, reducing the maximum length by $150-200$ residues for the $50-\mu \mathrm{M}$ dose. The reduction of poly(A) tail length in the cytoplasm could be secondary to a lack of polyadenylation in the nucleus, or could be due to effects on cytoplasmic polyadenylation. We therefore examined newly made mRNA by labeling HeLa cell RNA with thiouridine in the presence or absence of cordycepin for $2 \mathrm{~h}$. After RNA isolation, the labeled RNA was recovered by coupling of the incorporated thiouridine with biotin and binding to streptavidin magnetic beads. Streptavidinbound RNA has been synthesized within the last $2 \mathrm{~h}$, while unbound RNA is predominantly older than $2 \mathrm{~h}$. As can be seen in Figure 1B, a strong effect of cordycepin on poly(A) tails was observed in the bound RNA, while little effect was seen in the unbound RNA. These data show that cordycepin acts predominantly on newly synthesized RNA, consistent with an effect on transcription-coupled polyadenylation.

\section{Cordycepin-terminated poly(A) tails appear not to accumulate}

A caveat of the experiments described above is that any poly(A) tails that are terminated by cordycepin would not be labeled using the method above. Because poly(A) ribonuclease (PARN) is inhibited by the presence of cordycepin at the $3^{\prime}$ end of a poly(A) tail (Åstrom et al. 1991), it is even possible that the tails are actually longer than in untreated 
A

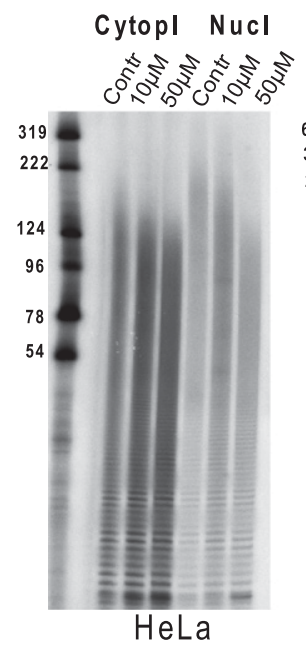

Cytopl Nucl

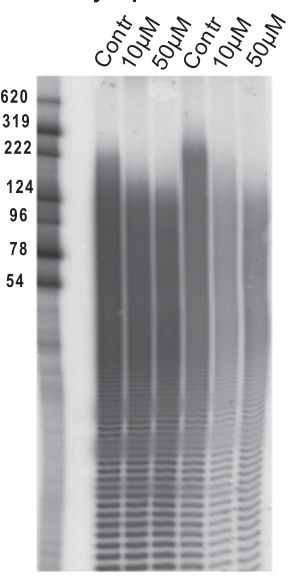

NIH 3 T3
B

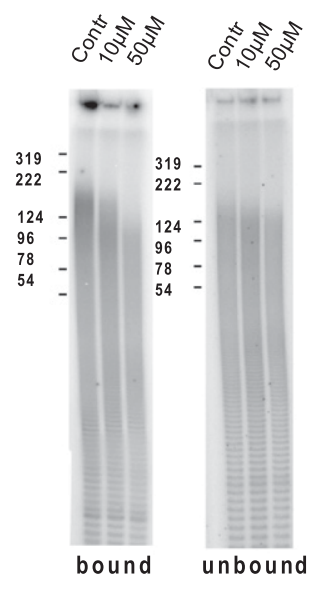

C

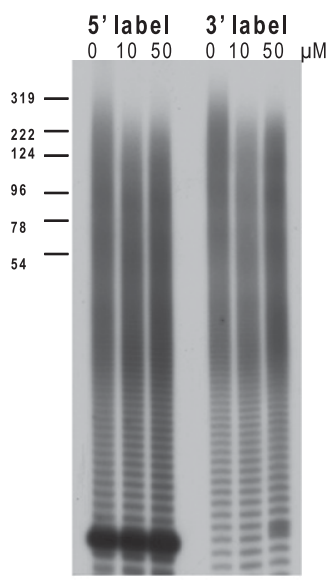

FIGURE 1. Cordycepin inhibits the nuclear polyadenylation of newly transcribed mRNAs. Total RNA was isolated from tissue culture cells treated with the indicated concentrations of cordycepin for $2 \mathrm{~h}$. The RNA was $3^{\prime}$ end-labeled and non-poly(A) RNA degraded, resulting in a smear representing the total poly(A) in the cell. Occasionally, discrete bands were observed and probably represent incompletely digested highly structured ribosomal RNA superimposed on the poly(A) pattern. These experiments are representative. (A) Poly(A) tails in cytoplasmic and nuclear RNA from HeLa and NIH3T3 cells. (B) Poly(A) tails in newly synthesized RNA recovered by purification of RNA labeled in HeLa cells with thiouridine and the indicated dose of cordycepin for $2 \mathrm{~h}$. (C) HeLa cells were treated with cordycepin, RNA isolated, and digested as described. The remaining poly(A) tails were isolated by oligo $\mathrm{d}(\mathrm{T})$ chromatography and labeled on the $5^{\prime}$ or $3^{\prime}$ end.

cells because cordycepin-terminated mRNAs may not be deadenylated. We therefore treated HeLa cells with cordycepin, isolated the RNA, and digested it with RNases A and T1to leave only poly(A) tails intact. The poly(A) tails were isolated by oligo $\mathrm{d}(\mathrm{T})$ chromatography and labeled on the $5^{\prime}$ end using T4 polynucleotide kinase or on the $3^{\prime}$ end using RNA ligase. The labeled RNA was subjected to denaturing polyacrylamide electrophoresis. If a significant percentage of poly(A) tails are terminated by cordycepin it should cause these tails to be either shorter (through chain termination) or longer (through inhibition of deadenylation). In either case, we would expect to observe cordycepin-induced differences in the distribution and relative intensity of labeling between $5^{\prime}$ and $3^{\prime}$ labeling of poly(A) tails. As can be seen in Figure 1C, no such differences were detected. We can conclude that poly(A) tails in cordycepintreated cells are indeed shortened and that there appears to be no significant accumulation of mRNAs with poly(A) tails that terminate in a cordycepin phosphate residue.

\section{Cordycepin reduces the response to TNF in human airway smooth muscle cells}

To elucidate the mechanism of action of cordycepin, we chose to study the induction of inflammatory mRNAs by tumor necrosis factor (TNF) in primary human airway smooth muscle (ASM) cells. This system has relevance for chronic inflammatory diseases such as asthma and chronic obstructive pulmonary disease. Other considerations were that the inflammatory response is well-defined and that we can exclude effects through repression of mTOR signaling on protein synthesis (Wong et al. 2010) by using serumdeprived cells in which this pathway is already repressed. To confirm the suitability of the system, we determined protein synthesis rates in the presence of cordycepin and TNF by the incorporation of radioactive amino acids. In this and all following experiments, unless indicated differently, cells were serum starved overnight and treated with 0 , 10 , or $50 \mu \mathrm{M}$ cordycepin for $30 \mathrm{~min}$, after which TNF was added and the cells were incubated for $1 \mathrm{~h}$. To determine protein synthesis rates, the cells were incubated with ${ }^{35} \mathrm{~S}$ label for $20 \mathrm{~min}$, and incorporated radioactivity was precipitated with TCA before scintillation counting. TNF treatment led to a small increase in protein synthesis. As expected, protein synthesis was not inhibited by cordycepin (Fig. 2A), even leading to a small increase of incorporation in untreated cells. Using the MTT metabolic cell viability assay, we determined that cordycepin also did not affect cell survival (Fig. 2B). In contrast, cordycepin still affects nuclear poly(A) tail length when we examine total poly(A) tails in RNA from cells treated with cordycepin and TNF as described, using the end-labeling method as in Figure 1 (Fig. 2C).

To examine the effect of cordycepin on inflammatory mRNA expression, ASM cells were incubated for $30 \mathrm{~min}$ with the indicated concentrations of cordycepin, and then TNF was added. RNA was isolated at the specified times after TNF addition, and mRNA levels were determined by RT-qPCR. Normalization was to GAPDH mRNA. As in all of the following experiments, unless indicated differently, three biological replicates were performed. As can be seen in Figure 3A, cordycepin significantly inhibited the accumulation of all six inflammatory response mRNAs tested (CXCL1, 


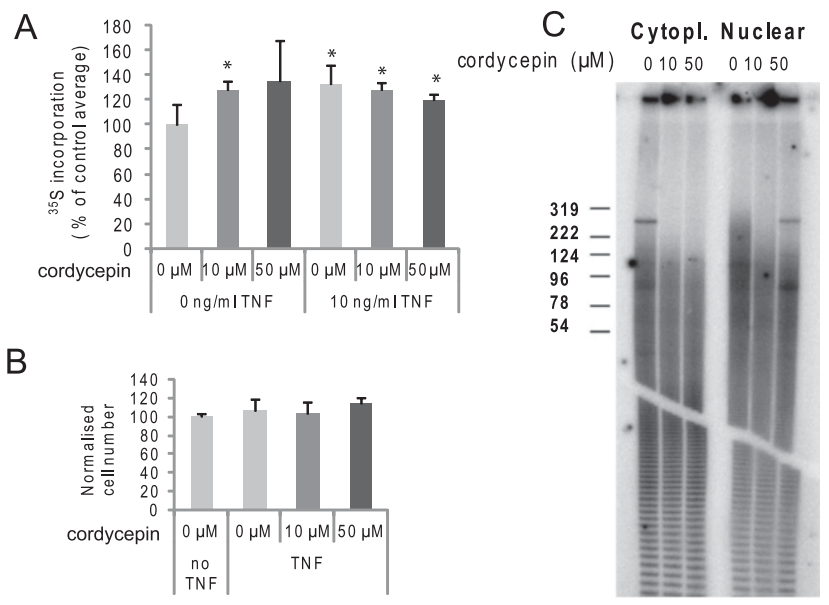

FIGURE 2. The effect of cordycepin on ASM cells. (A) Cordycepin does not repress protein synthesis in serum-starved ASM cells in the presence or absence of TNF. Incorporation of $S^{35}$-labeled amino acids in protein in the presence of the indicated compounds. Cordycepin was added first, TNF and ${ }^{35}$ S-label 30 min later for $1 \mathrm{~h}$, and labeling was performed after this for $20 \mathrm{~min}$. Error bars show standard deviations over four replicates. Incorporation was determined as previously described (Wong et al. 2010). Statistical significance in a paired $T$-test for comparison with the untreated control (no TNF, no cordycepin) is indicated, $\left(^{*}\right) P \leq 0.05$. (B) Cordycepin does not change cell viability. Cell number was determined after $8 \mathrm{~h}$ of incubation with cordycepin using the MTT assay. Error bars represent standard deviations over four replicates. $(C)$ Cordycepin inhibits nuclear polyadenylation in airway smooth muscle cells. End labeling on cytoplasmic and nuclear RNA was performed as for Figure 1A.

IL8, CCL2, LIF, CCL11, VCAM1). These included both transient and persistently induced genes. However, cordycepin did not affect the levels of housekeeping mRNAs encoding $\beta$ actin (ACTB) and a ribosomal protein (RPL10A), nor the levels of rarer noninflammatory mRNAs encoding the nuclear exosome subunit (EXOSC10), the kinase AKT1, or the tumor suppressor p53 (TP53). The cell cycle inhibitor p21 (CDKN1A) was weakly induced during the first hour of TNF treatment and then down-regulated. This was not affected by cordycepin treatment. Because TNF does not induce the important inflammatory gene PTGS2 (COX2) in these cells (Pang and Knox 1997), we treated ASM cells with interleukin $1 \beta$ after a 30 -min preincubation with different doses of cordycepin, and found that PTGS2 mRNA induction is also very sensitive to cordycepin treatment (Fig. 3B). The effect on the mRNA levels was also reflected in the protein levels, as determined by Western blot on cellular lysate for PTGS2 and by ELISA on medium for IL8, CCL2, and CCL11 (Fig. 3B,C). These data demonstrate that inflammatory gene induction by two pro-inflammatory cytokines is effectively blocked by cordycepin in ASM cells.

\section{Cordycepin specifically inhibits inflammatory gene expression}

Because of the high stability of mRNAs for housekeeping proteins such as RPL10A and GAPDH, changes in their synthesis may not be detected in Figure 3A. We therefore used thiouridine labeling to isolate newly made mRNA. Labeled RNA recovered in the bound fraction represents mRNA synthesized during the labeling period, in which both housekeeping and inflammatory mRNAs are being transcribed. ASM cells were treated with cordycepin at the specified concentrations for $1 \mathrm{~h}$ and TNF was added. Thiouridine was added $15 \mathrm{~min}$ after the start of TNF treatment and the cells were incubated for another $45 \mathrm{~min}$. Total RNA was isolated, labeled with biotin, and purified using streptavidin beads. Purified labeled RNA was reverse transcribed and subjected to qPCR. Normalization was to ribosomal RNA, as this is very stable but still significantly transcribed in the time period. As can be seen in Figure 4A, the effect of cordycepin on inflammatory gene expression was even more pronounced using this method (CXCL1, IL8, and LIF), but no effects were detected on the control mRNAs that were transcribed in the same time period (GAPDH, RPL10A, and ACTB). To exclude the possibility that the observed lack of effect on the control mRNAs is due to nonspecific binding of these abundant mRNAs to the streptavidin beads, we repeated the experiment with a control in which thiouridine label was omitted. As can be seen in Figure 4B, levels of these mRNAs were very low in this control. Cordycepin does, therefore, specifically affect the expression of inflammatory mRNAs and not of housekeeping mRNAs, even though both of these classes of mRNAs are known to be subject to polyadenylation.

\section{Effects of cordycepin do not correlate with mRNA stability}

In a previous publication, we suggested that cordycepin could be specifically affecting unstable mRNAs (Wong et al. 2010). The inflammatory mRNAs are well known to have a large spectrum of stabilities and this is a major determinant in the kinetics of their induction (Hao and Baltimore 2009). We therefore tested the stability of the inflammatory mRNAs in our system by inducing mRNAs with TNF for $1 \mathrm{~h}$ and adding the transcripton inhibitor actinomycin $\mathrm{D}$ with or without the indicated concentrations of cordycepin. RNA was isolated at timepoints up to $4 \mathrm{~h}$ after actinomycin D addition and analyzed by RT-qPCR with normalization to GAPDH mRNA. Inflammatory mRNA half-lives have been reported to vary from $45 \mathrm{~min}$ (CXCL1) to $>4 \mathrm{~h}$ (CCL11) (Hao and Baltimore 2009). The data presented in Figure 4C largely confirm that this is also the case in ASM cells. However, for the CCL11 and VCAM1 mRNAs, levels appear to rise over time. This rise is not due to a reactivation of transcription, as unspliced VCAM1 pre-mRNA levels remain very low ("VCAM1 unspliced" panel in Fig. 4C). Presumably, at the later timepoints these mRNAs are more stable than the control RPL10A and ACTB control mRNAs and the GAPDH mRNA to which the qPCR data are normalized. CDKN1A mRNA was unstable with a half-life of $\sim 80 \mathrm{~min}$. 


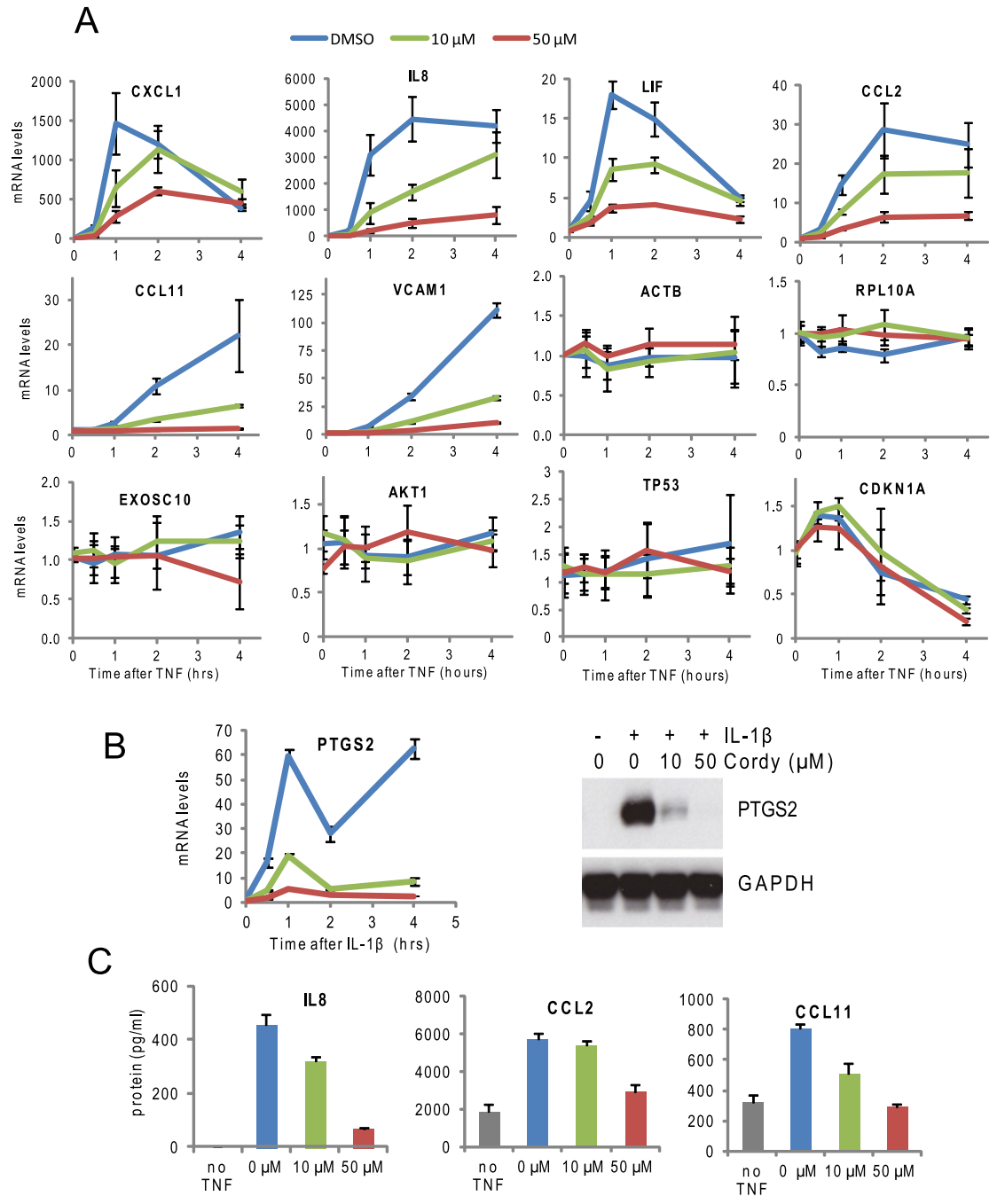

FIGURE 3. Cordycepin inhibits the accumulation of inflammatory mRNAs. (A) Primary human airway smooth muscle (ASM) cells were pretreated with the indicated concentrations of cordycepin for $30 \mathrm{~min}$ before treatment with inflammatory cytokines. RNA was isolated at the indicated times, RT-qPCR performed for the indicated mRNAs, and the mRNA levels expressed relative to GAPDH mRNA. Untreated control values (no TNF, no cordycepin) were set at 1 . (B) PTGS2 mRNA levels expressed as in $A$ from cells treated with interleukin $1 \beta$ (IL-1 $\beta$ ), and Western blot for PTGS2 from cells treated for $8 \mathrm{~h}$ in this manner. (C) Cytokine and chemokine production is affected by cordycepin treatment. Cytokine and chemokine levels in medium from cells treated as in $A$, incubated for $4 \mathrm{~h}$, determined by ELISA. All error bars in this figure are standard deviations over three biological replicates.

Addition of cordycepin at the same time as actinomycin $\mathrm{D}$ had no effect on the decay of the short-lived inflammatory mRNAs (CXCL1, IL8, and CCL2), and caused only a small increase in degradation at the earlier timepoints for the long-lived mRNAs (VCAM1 and CCL11). This latter effect may indicate that mRNAs recently transcribed from the VCAM1 and CCL11 genes are still sensitive to cordycepin, but mRNAs older than $30 \mathrm{~min}$ are unaffected. The control mRNAs, RPL10A, ACTB, and CDKN1A were again unaffected by cordycepin treatment in this experiment. These data show that there is no significant correlation between the stability of an mRNA and its sensitivity to cordycepin. In addition, cordycepin treatment does not appear to affect the stability of mRNAs if they have been transcribed and processed in its absence.

\section{Cordycepin acts intracellularly and as a phosphorylated nucleotide}

Cordycepin has been described to influence gene expression by activating adenosine receptors (Nakamura et al. 2006; Kitamura et al. 2011). To investigate whether this is the case in ASM cells, we preincubated the cells with inhibitors of the adenosine transporter (nitrobenzylthioinosine, NBTI) and adenosine kinase (iodotubericidin, ITU) (Bontemps et al. 1983; Newby et al. 1983; Parkinson and Geiger 1996; Ward et al. 2000; SenGupta et al. 2002). Cells were then treated with cordycepin and TNF as previously described, RNA was isolated and subjected to RT-qPCR with normalization to GAPDH mRNA. As can be seen in Figure 5A, the inhibitors completely abrogated the effect of cordycepin on the induction of IL8 mRNA, indicating that cordycepin has to enter the cell using the adenosine transporter and be phosphorylated by adenosine kinase to affect the inflammatory response.

\section{Cordycepin does not affect recruitment of NFKB or RNA polymerase to the promoter}

As described in the introduction, TNF binding to its receptor ultimately leads to degradation of $\mathrm{I} \kappa \mathrm{B}$, which causes nuclear import of the NFкB transcription factors and their binding to the promoter of inflammatory genes. To assess whether cordycepin inhibits inflammatory gene expression at the level of NFкB import, we investigated the degradation of IкB and the nuclear translocation of $\mathrm{NF} \kappa \mathrm{B}$ in the presence of cordycepin by cell fractionation and Western blotting after treating ASM cells with cordycepin and TNF as previously described. As can be seen in Figure 5, B and C, neither of these processes were affected. To investigate whether the DNA binding of NFKB or the recruitment of RNA polymerase to the inflammatory gene promoters was affected, we isolated nuclei from ASM cells treated with cordycepin for $30 \mathrm{~min}$ before the addition of TNF and incubation for another $30 \mathrm{~min}$. Chromatin 
A
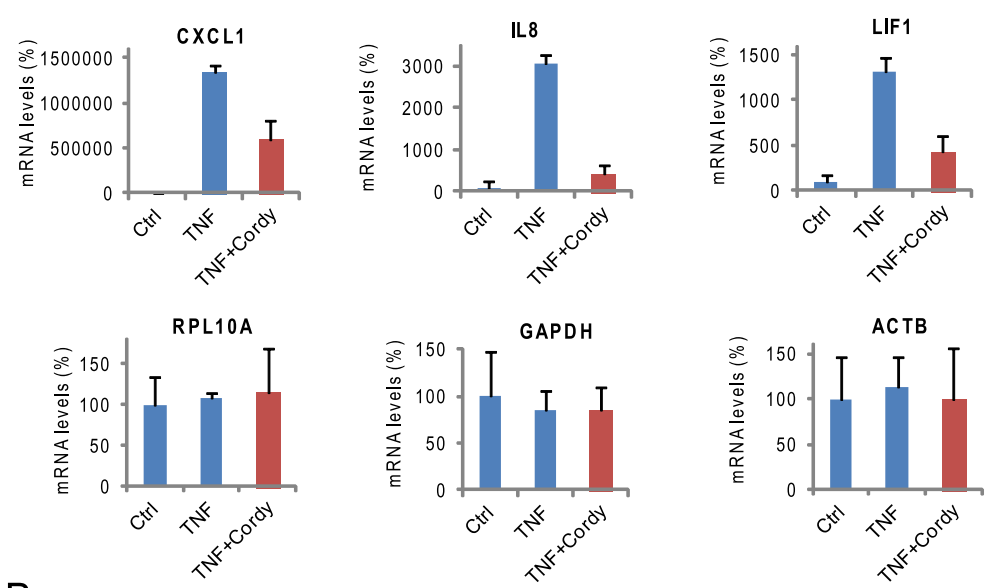

B
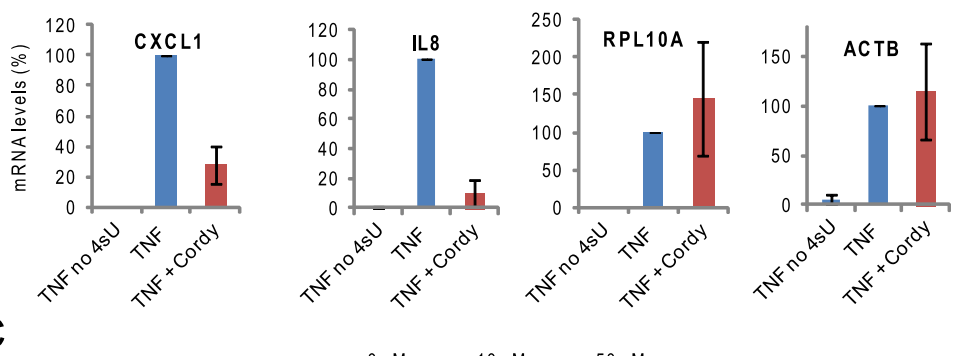

C
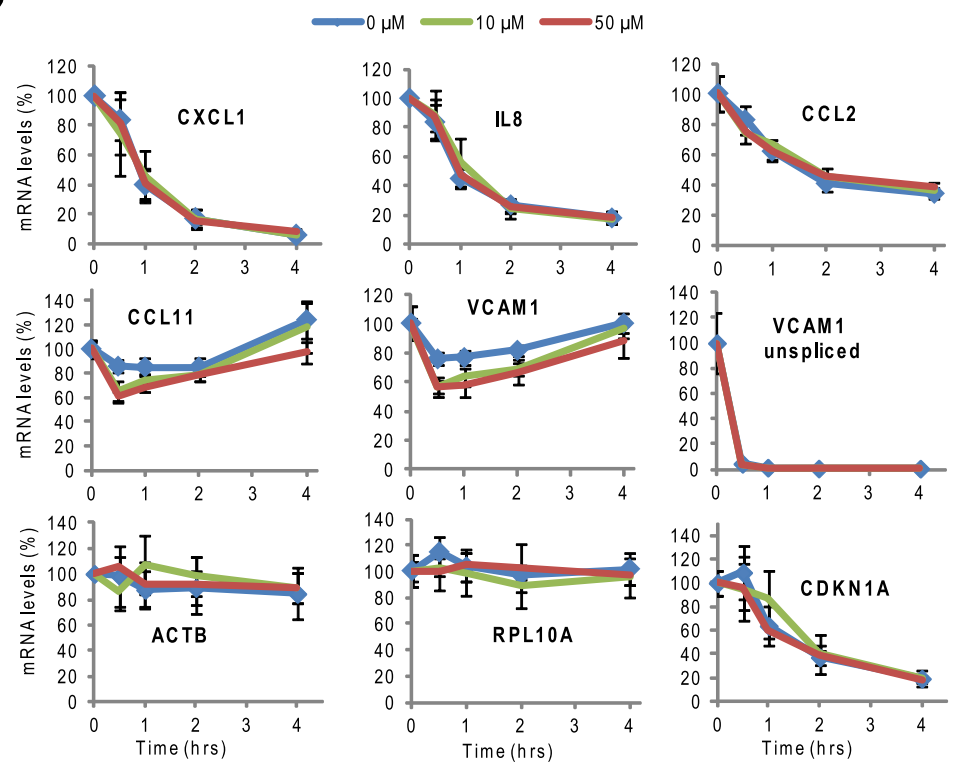

FIGURE 4. The effect of cordycepin is gene specific and unrelated to mRNA stability. (A) ASM cells were pretreated with cordycepin $(50 \mu \mathrm{M})$ or vehicle for $60 \mathrm{~min}$, then TNF or vehicle (Ctrl) was added. Fifteen minutes after TNF or vehicle addition, $500 \mu \mathrm{M}$ thiouridine was added. Cells were lysed $45 \mathrm{~min}$ after addition of thiouridine, RNA was isolated, and thiouridine-labeled RNA was purified as described. RT-qPCR for the indicated mRNAs was performed and normalized to RT-qPCR values for ribosomal 18S RNA. Values shown are relative to the average value for untreated. Error bars represent standard deviations over thee biological replicates. $(B)$ ASM cells were treated with TNF in the presence or absence of cordycepin as described in $A$, but thiouridine was left out in one plate of cells (TNF no $4 \mathrm{sU}$ ). Values shown are relative to the TNF induced signal (TNF) in each replicate. Error bars represent standard deviations over two biological replicates. $(C)$ Airway smooth muscle cells were treated with TNF for $1 \mathrm{~h}$, when $5 \mu \mathrm{g} / \mathrm{mL}$ of the transcription inhibitor actinomycin $\mathrm{D}$ was added with or without cordycepin at the indicated concentrations. RNA was isolated at the indicated times and RT-qPCR performed as described. Error bars are standard deviations over three biological replicates. immunoprecipitation (ChIP) for the relA subunit of $\mathrm{NF \kappa B}$ (p65) and for RNA polymerase was performed, followed by quantitative PCR (qPCR) with primers for the promoter regions. As can been seen in Figure 5D, cordycepin did not decrease the binding of $\mathrm{NF \kappa B}$ or RNA polymerase to the promoter in response to TNF treatment for any of the inflammatory genes examined (CXCL1, IL8, and CCL2). In fact, promoter recruitment of RNA polymerase was increased by $40 \%$ for CXCL1. We can conclude that the signal transduction leading to recruitement of RNA polymerase complexes on inflammatory genes is not inhibited by cordycepin in these cells. In order to determine the effects of cordycepin on termination of RNA polymerase II, we performed ChIP, followed by qPCR, with primers for the terminator regions $3^{\prime}$ of the cleavage site. The signal here and in the body of the genes was very low and we could only obtain reliable results for the CXCL1 gene, as shown in Figure 5F. The association of RNA polymerase was not significantly altered for the exon 2/intron 2 boundary, the poly(A) site, or $750 \mathrm{nt}$ downstream from the cleavage site, but there was a clear increase in RNA polymerase levels $1700 \mathrm{nt}$ downstream from the cleavage site, suggestive of a termination defect.

\section{Cordycepin acts post-transcriptionally on CXCL1 and CCL2, but not on IL8}

To determine whether the effect of cordycepin is post-transcriptional, we measured the levels of unspliced premRNA in cordycepin and TNF-treated ASM cells using RT-qPCR and the primers depicted in Figure 5E. Normalization was to GAPDH mRNA. As can be seen in Figure 6A, cordycepin increased the levels of unspliced premRNA for CXCL1, indicating that the increase in RNA polymerase levels on the promoter found in Figure 5D does indeed lead to increased transcription. Unspliced pre-mRNA for CCL2 was unaltered by cordycepin treatment. These data show that the 

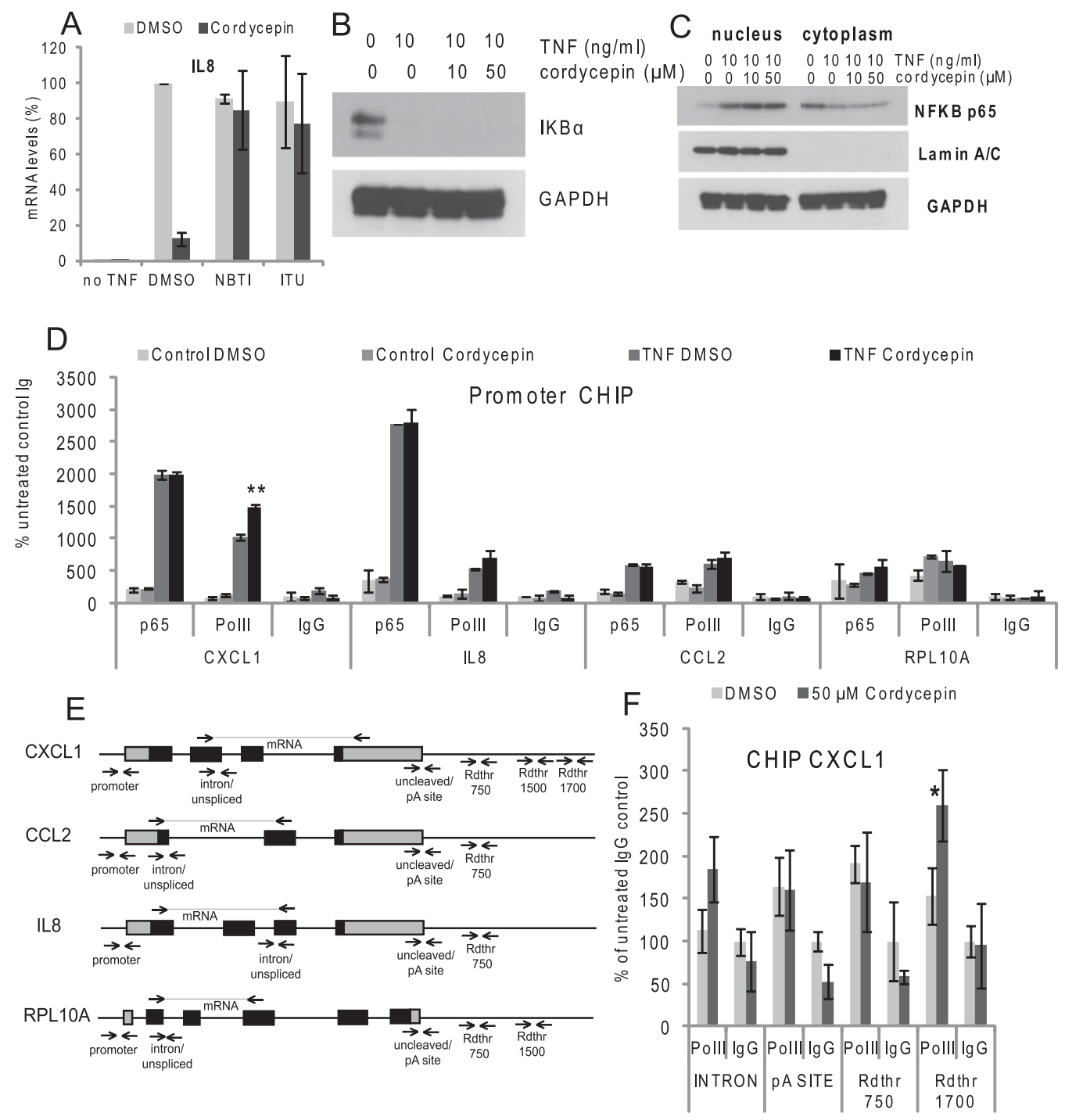

FIGURE 5. Cordycepin does not prevent recruitment of NFKB or RNA polymerase in human airway smooth muscle cells. $(A)$ To repress inflammatory gene expression, cordycepin has to be imported and phosphorylated. Cordycepin import was inhibited with 10 mM NBTI, while cordycepin phosphorylation was inhibited with $0.1 \mathrm{mM}$ ITU and cells were treated with cordycepin and TNF as previously. Values shown are relative to the TNF-induced signal (DMSO, no cordycepin) in each replicate. Error bars show standard deviations over two biological replicates. $(B) \mathrm{I} \kappa \mathrm{B} \alpha$ is degraded normally in human airway smooth muscle cells treated with cordycepin. Cells treated as in Figure 3A: 30-min pretreatment with cordycepin, followed by 30-min TNF treatment. (C) Cordycepin does not inhibit nuclear import of the p65 subunit of NFkB. Airway smooth muscle cells were pretreated with cordycepin for $30 \mathrm{~min}$ and incubated with TNF for $30 \mathrm{~min}$. Nuclear and cytoplasmic extracts were prepared and subjected to Western blotting for the indicated proteins. (D) RNA polymerase recruitment is not inhibited. Chromatin immunoprecipitation (ChIP) was performed with antibodies against NFKB (p65) and RNA polymerase II subunits on chromatin from human airway smooth muscle cells. If indicated, cells were pretreated with cordycepin for 30 min before TNF was added for 30 min, and cells were harvested. qPCR using primers for the promoters of the genes indicated. Values are expressed as the \% signal relative to the background (control IgG IP of untreated sample). (E) Four genes with the location of the primers used in Figures 5 and 6 . Primer sequences can be found in Supplemental Table 1. (F) There appears to be a termination defect. qPCR on RNA polymerase ChIP samples prepared as described for $D$, using primers in the middle and $3^{\prime}$ end of the CXCL1 gene. All error bars for the ChIP data are standard deviations over three biological replicates, except the first column in $C$, which is a duplicate. Statistical significance in a paired $T$-test for comparison with noncordycepin treated is indicated: $\left({ }^{*}\right) P \leq 0.05,\left(^{* *}\right) P \leq 0.01$.

cordycepin-induced reduction in gene expression is entirely post-transcriptional for CXCL1 and CCL2. In contrast, IL8 pre-mRNA levels were severely reduced by cordycepin, despite the lack of effect on the recruitment of RNA polymerase to the promoter, indicating an effecton transcription elongation.

\section{Cordycepin causes transcription termination and cleavage defects}

The results in Figure 5F indicate that RNA polymerase is not released properly after transcribing the gene, and therefore is found further downstream from the polyadenyation site. 

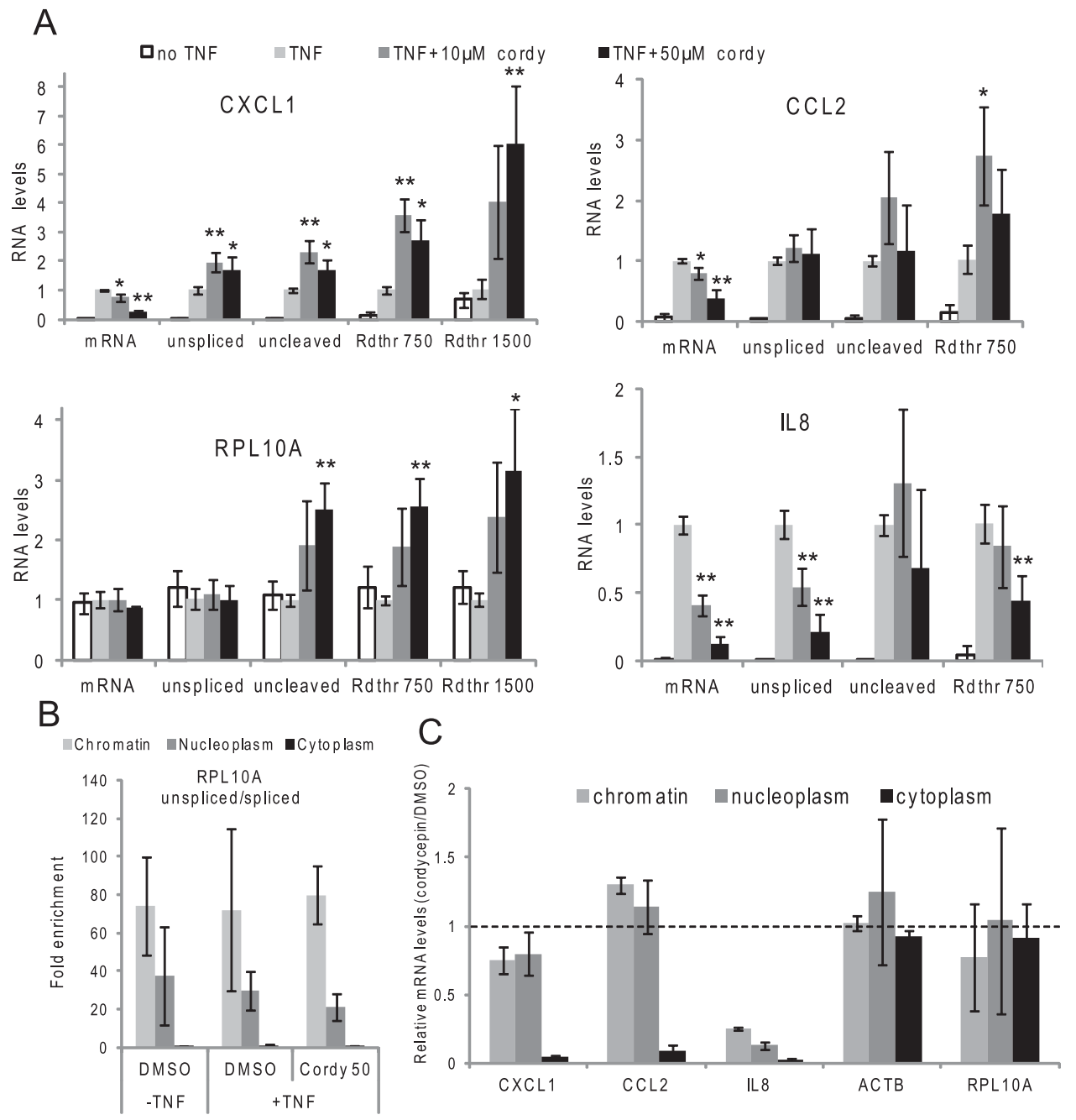

FIGURE 6. Effects of cordycepin on nascent and mature mRNA. (A) RNA was isolated from ASM cells. RT-qPCR was performed for mature mRNA (mRNA), unspliced pre-mRNA (unspliced), uncleaved pre-mRNA (uncleaved), and for runthrough RNA transcribed from the terminator region, 750 or $1500 \mathrm{nt}$ from the cleavage site (Rdthr750 and Rdthr1500). The location of the primers used is indicated in Figure 5B. mRNA levels were normalized to GAPDH mRNA levels. All error bars in this figure are standard deviations over three biological replicates. Statistical significance in a paired $T$-test for comparison with noncordycepin treated is indicated: $\left(^{\star}\right) P \leq 0.05,\left({ }^{*}\right) P \leq 0.01$. (B) Chromatin associated, nucleoplasmic and cytoplasmic fractions are successfully separated. RNA fractions were isolated and RT-qPCR for spliced and unspliced RPL10A mRNA was performed. The ratio of unspliced over spliced for each sample was divided by this ratio in the cytoplasmic fraction. Error bars represent standard deviations over three biological replicates. $(C)$ The effect of cordycepin (Cordy) on inflammatory and control mRNA levels in chromatin-associated, nucleoplasmic, and cytoplasmic RNA isolated from TNF-treated ASM cells, as determined by RT-qPCR. Data were normalized to GAPDH mRNA levels, and the ratio between cordycepin-treated and noncordycepin-treated samples was graphed (a value of 1 therefore indicating no change). Error bars represent standard deviations over three biological replicates.

This is a transcription termination defect that is observed if the efficiency of pre-mRNA cleavage is reduced (Luo et al. 2006; West et al. 2008; Richard and Manley 2009). We therefore examined the levels of uncleaved pre-mRNA and runthrough transcripts in total RNA isolated from ASM cells treated with cordycepin and TNF as described previously using RT-qPCR with the primers indicated in Figure 5E. The data in Figure 6A clearly show that uncleaved and runthrough transcripts were increased in cordycepin-treated cells for both CXCL1 and the control RPL10A gene. CCL2 exhibited the same effect to a lesser extent. The reduction in transcription on the IL8 gene was evident for all primer pairs, except the uncleaved, which had very large variability. The IL8 terminator RNA was less reduced than the unspliced mRNA, indicating that termination defects may also be occurring in addition to the transcription reduction. These data demonstrate that cordycepin causes defects in transcription termination and mRNA cleavage on both control and inflammatory genes.

To examine at what stage the CCL2 and IL8 transcripts disappear during cordycepin treatment, we examined the levels of cytoplasmic, nucleoplasmic, and chromatin-associated RNA 
isolated from cordycepin and TNF-treated ASM cells by RTqPCR, normalized to GAPDH mRNA. Our fractionation method was validated by a strong observed enrichment of unspliced RPL10A pre-mRNA in the chromatin-associated fraction (Fig. 6B) and a lack of pre-mRNA amplification in the absence of reverse transcription, indicating that the genomic DNA has been effectively removed from the chromatin-associated RNA preparation. As can be seen in Figure 6C, CXCL1 and CCL2 mRNA levels were affected only marginally by cordycepin treatment in the chromatin and nucleoplasmic fraction, but the mRNA is virtually absent from the cytoplasm. These data indicate once more that the effect of cordycepin on CXCL1 and CCL2 mRNAs is posttranscriptional and suggest that the mRNAs are degraded during or immediately after nuclear export. While IL8 mRNA levels were strongly reduced in chromatin-associated mRNA, confirming an effect on IL8 transcription, further reductions were observed both in nucleoplasm and in cytoplasm, indicating that posttranscriptional effects also contribute to the reduction of IL8 levels in the presence of cordycepin.

\section{Polyadenylation-competent 3 ' sequences are required for cordycepin sensitivity}

We then sought to determine whether sequences in the $3^{\prime}$ end of the gene influence cordycepin sensitivity. We constructed luciferase reporter constructs under the control of a synthetic NFKBdependent promoter. In one construct we placed a histone $3^{\prime}$ UTR and terminator sequences. This construct should be processed and terminated independently of polyadenylation, and therefore be insensitive to cordycepin. We also constructed reporters with the SV40 polyadenylation signal and terminator sequences from the $\beta$ globin and CXCL1 genes, as well as a construct containing both the CXCL1 3' UTR and poly(A) signal and its terminator sequences. These reporters are depicted in Figure 7A. For the transfection experiments, we chose to work with serumstarved A549 lung carcinoma cells, as the batch of ASM cells we used throughout this study gave very poor transfection efficiencies. A549 cells respond to TNF, although not as strongly as ASM cells. As for the ASM cell treatment, A549 cells were serum starved overnight and treated with the indicated doses of cordycepin for $30 \mathrm{~min}$, followed by a 1-h treatment with TNF. The induction of cytokine mRNAs was reduced by cordycepin to $70 \%-50 \%$ (Fig. 7B). We transfected A549 cells with these constructs, changed the medium to serumfree after $24 \mathrm{~h}$, and examined the luciferase activity $24 \mathrm{~h}$ later, either without stimulation or $2 \mathrm{~h}$ after TNF treatment. As can be seen in Figure 7C, the luciferase activity produced by the reporter gene with histone $\mathrm{H} 4$ cleavage and termination sequences was insensitive to cordycepin treatment. In contrast, the SV40 poly(A) signal with $\beta$ globin terminator sequences showed some sensitivity to cordycepin, reducing induction by $20 \%$ at the highest dose. Similarly, the activity of the construct with the SV40 poly(A) signal and the CXCL1 terminator (pCXCL1Ter)

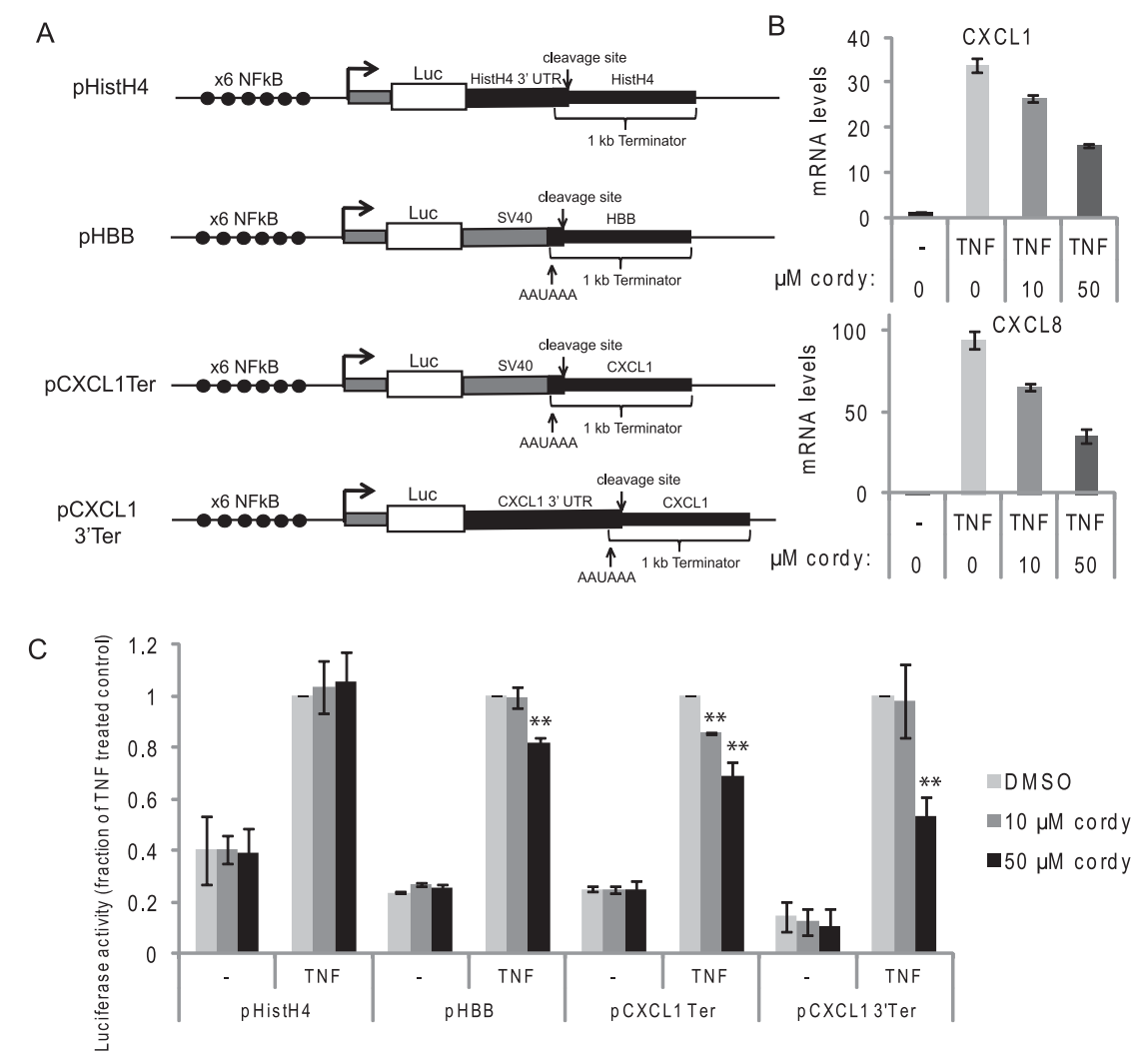

FIGURE 7. Cordycepin sensitivity of reporter genes requires $3^{\prime}$ sequences. (A) NFkB responsive firefly luciferase reporter genes with terminator or $3^{\prime}$ UTR sequences from the CXCL1 (pCXCL1-Ter, pCXCL1-3'Ter), histone H4 (pHistH4), and $\beta$ globin (pHBB) genes were constructed. (Black circles) NFKB binding sites; (arrow) promoter start; (gray boxes) SV40 derived 5' and 3' UTR sequences; (white box) luciferase coding region; (black boxes) 3' sequences from the indicated human genes. Sizes of these regions are not to scale. $(B)$ TNFinduced chemokine mRNA induction in A549 cells is also sensitive to cordycepin. mRNA levels were determined as previously after $1 \mathrm{~h}$ TNF induction as described for Figure 3A. Error bars represent 1 standard deviation over three qPCR replicates. This is a representative experiment of several performed under similar but not identical conditions. (C) These reporters were transfected into A549 cells and the cells were treated with TNF in the absence or presence of cordycepin for $2 \mathrm{~h}$. The induction in the control cells (with TNF, no cordycepin) was set at 1 for each construct. Error bars in this figure are standard deviations over three independent biological replicates. Statistical significance in a paired $T$-test for comparison with noncordycepin treated is indicated: $\left(^{*}\right) P \leq 0.05,\left({ }^{* *}\right) P \leq 0.01$. 
was reduced by $30 \%$ by $50 \mu \mathrm{M}$ cordycepin. The combination of CXCL1 3' UTR and terminator (pCXCL13'Ter) showed a further repression to nearly $50 \%$, indicating that both regions contain sequences necessary for full cordycepin sensitivity. These data show that a reporter that is not dependent on polyadenylation is not sensitive to cordycepin, indicating that cordycepin is indeed acting through the inhibition of polyadenylation. Furthermore, the sensitivity to cordycepin is enhanced by sequences in the $3^{\prime}$ UTR of the CXCL1 gene.

\section{Other methods of polyadenylation inhibition also affect the inflammatory response}

The data shown above are consistent with inhibition of polyadenylation being the primary mode of action of cordycepin for the repression of inflammatory responses. To confirm this mechanism, we used another adenosine analog known to mediate chain termination of polyadenylation, 8-aminoadenosine (Chen et al. 2009). Using the end-labeling protocol outlined before, we confirmed that this analog affects poly(A) tail size in airway smooth muscle cells, while other adenosine analogues (8-chloroadenosine and 8-bromoadenosine) did not (Fig. 8A). Strikingly, a 30-min preincubation with 8 -aminoadenosine prevented the accumulation of inflammatory mRNAs in response to TNF in ASM cells, while incubation with 8-chloroadenosine did not. This demonstrates that of the adenosine analogs we tested, only the polyadenylation inhibitors have anti-inflammatory properties (Fig. 8B).

As another method for reducing polyadenylation activity, we knocked down the mRNA for the main nuclear poly(A) polymerase, poly(A) polymerase $\alpha$ (PAPOLA) using siRNA transfection in A549 and airway smooth muscle cells. Knockdown of PAPOLA mRNA reduced the protein levels to $15 \%-20 \%$ of control as measured by Western blotting, but end labeling of poly(A) tails showed that the influence on total poly (A) tail size in the cells was small, indicating that other poly(A) polymerases make major contributions in these cells (Fig. 8C,D). However, knockdown of PAPOLA is sufficient to significantly reduce the induction of CXCL1, IL8, and CCL2 mRNA by a 1-h TNF $\left.{ }^{* * *}\right) P \leq 0.001$. treatment in ASM cells, demonstrating the sensitivity of inflammatory gene expression to the inhibition of polyadenylation (Fig. 8E). Control mRNAs were unaffected by PAPOLA knockdown at the time of measurement, $50 \mathrm{~h}$ after the initial siRNA treatment. These data indicate that the effects of cordycepin on inflammatory gene expression are indeed mediated through its effects on polyadenylation.

\section{DISCUSSION}

In this study we show that the effects of cordycepin on inflammatory gene expression in airway smooth muscle cells are gene specific and likely to be mediated by inhibition of polyadenylation and/or $3^{\prime}$ processing. Cordycepin inhibits the accumulation of inflammatory mRNAs, but not of housekeeping mRNAs (Figs. 3, 4). Contrary to our previous

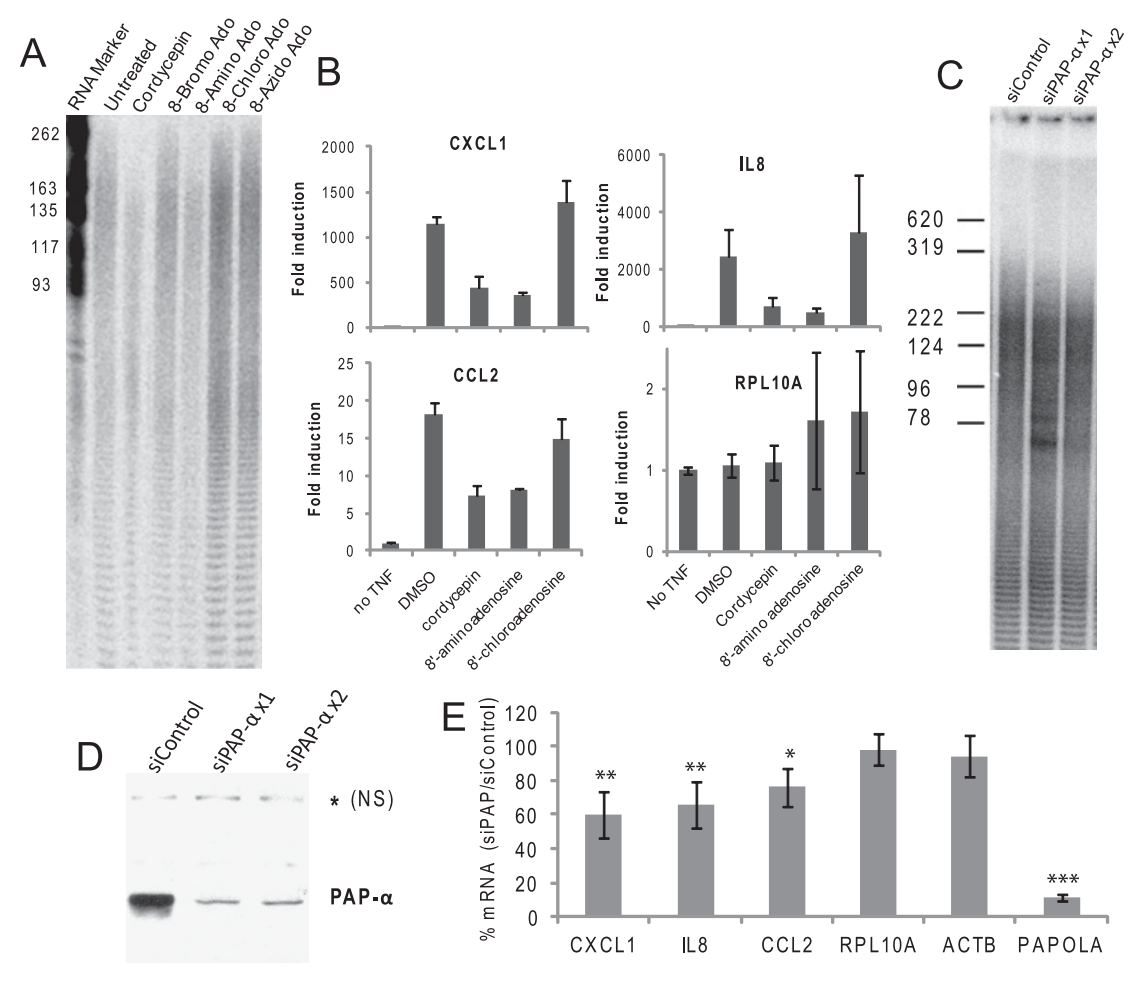

FIGURE 8. Inhibition of polyadenylation reduces the inflammatory response. (A) 8-Aminoadenosine but not 8-chloroadenosine inhibits polyadenylation. End-labeling was performed as described for Figure 1 on RNA from NIH3T3 cells treated with $50 \mu \mathrm{M}$ of the indicated adenonsine (ado) derivatives for $2 \mathrm{~h}$. (B) 8-aminoadenosine also inhibits accumulation of inflammatory mRNAs. Airway smooth muscle cells were pretreated for 30 min with $50 \mu \mathrm{M}$ of the indicated compounds, after which TNF was added and RNA was isolated $1 \mathrm{~h}$ later. RTqPCR for the indicated mRNAs was performed as described on three biological replicates. $(C)$ Knockdown of PAPOLA has little effect on total poly(A) tails. RNA from A549 cells treated once $(\times 1)$ or twice $(\times 2)$ with siRNAs was analyzed by end labeling as described for Figure 1 . (D) Western blot for PAP $\alpha$ shows the siRNA knockdown is successful. A nonspecific band (NS) serves as a loading control. (E) Knockdown of PAPOLA reduces the induction of CXCL1, IL8, and CCL2. Airway smooth muscle cells were treated with control siRNA or siRNA against the mRNA for PAPOLA (poly(A) polymerase $\alpha$ ). Cells were treated for $1 \mathrm{~h}$ with TNF and RNA was isolated. RT-qPCR for the indicated mRNAs was performed as described. Values are shown as $\%$ of control siRNA treated for four biological replicates. The $P$-values were calculated by comparing with RPL10A using an unpaired T-test: $\left(^{*}\right) P \leq 0.05,\left({ }^{* *}\right) P \leq 0.01$, 
hypothesis, the effect appears not to be related to the stability of the mRNAs, because relatively stable transcripts like CCL11 and VCAM1 are also affected (Figs. 3A, 4C; Wong et al. 2010). Promoter binding of RNA polymerase is not reduced, also ruling out effects on $\mathrm{NF \kappa B}$ recruitment and function (Figs. 5, 6). A reporter gene with histone 3' processing signals was not sensitive to cordycepin, indicating that polyadenylation-dependent $3^{\prime}$ processing is the target of cordycepin (Fig. 7). In addition, a different polyadenylation inhibitor and knockdown of PAP $\alpha$ also specifically inhibited the induction of inflammatory genes, demonstrating that inflammatory genes have a particular sensitivity to the inhibition of polyadenylation (Fig. 8).

For CXCL1 and CCL2 the effect is clearly posttranscriptional, as unspliced pre-mRNA expression and chromatin and nucleoplasmic mRNA levels are largely unaffected by cordycepin treatment (Fig. 6). The mRNAs appear to be degraded during or immediately after nuclear export. Presumably, these mRNAs are targeted for rapid degradation because of a lack of cleavage, an incomplete poly(A) tail, or a lack of deposition of nucleophosmin on the 3' end of the mRNA (Yen et al. 2004; Martick et al. 2008; Meaux et al. 2011; Sagawa et al. 2011). A fundamental difference between the inflammatory messenger ribonucleoprotein complexes (mRNPs) and the RPL10A mRNP must exist that exempts RPL10A mRNA from this degradation pathway, as the effects on termination and cleavage are similar for RPL10A and CXCL1. There may be specific sequences in the inflammatory gene transcripts mediating this difference, as our data indicate that the $3^{\prime}$ UTR and terminator sequences of CXCL1 contribute to cordycepin sensitivity (Fig. 7). For instance, 3' UTR sequences from inflammatory mRNAs could mediate extreme instability of transcripts with short poly(A) tails, or housekeeping mRNAs may contain $3^{\prime}$ UTR sequences stabilizing such transcripts. The degradation pathway of the inflammatory mRNAs synthesized in the presence of cordycepin appears to be similar to that reported for an mRNA cleaved by an atypical mechanism (Meaux et al. 2011), and is also consistent with effects of cordycepin on adenovirus mRNA expression (Zeevi et al. 1982).

For IL8, effects on unspliced mRNA are similar to those for mature mRNA, and both chromatin and nucleoplasmic mRNA levels are affected, indicating that despite the recruitment of RNA polymerase, transcription is inhibited during late initiation or during elongation (Figs. 5, 6). This phenomenon could be mediated through the recently reported effects of defects in $3^{\prime}$ processing on the recycling of transcription initiation and elongation factors from the terminator to the promoter (Mapendano et al. 2010). In addition, interactions between the transcription elongation factor PAF1c and the polyadenylation machinery could play a role (Rozenblatt-Rosen et al. 2009). The difference between the mechanism of action of cordycepin on the CXCL1 and IL8 genes may well lie in the weak poly(A) signal in the IL8 gene (AAUAUAA), which could make the gene more sensitive to defects in the coupling of transcription and $3^{\prime}$ processing.

There are eight candidate $\operatorname{poly}(\mathrm{A})$ polymerase genes in the human genome: PAP $\alpha-\gamma$ (PAPOLA,B,G), PAPD1, PAPD2, PAPD4, PAPD5, and PAPD7 (Hirose and Manley 1998; Wahle and Rüegsegger 1999; Topalian et al. 2001; Houseley and Tollervey 2008; Kashiwabara et al. 2008; Radford et al. 2008; Rammelt et al. 2011). They have a variety of substrates and functions, ranging from targeting aberrant transcripts for degradation in the nucleus to stabilizing microRNAs in the cytoplasm (Katoh et al. 2009; Shcherbik et al. 2010). Poly(A) polymerase $\alpha$ (PAP $\alpha$, official gene name PAPOLA) is the best-studied family member and has been presumed to be the main poly (A) polymerase for the nuclear polyadenylation of mRNAs. However, in a proteomic study of the mRNA polyadenylation complex, only its close relative PAP $\gamma$ was recovered (Shi et al. 2009). In addition, it has recently transpired that a subset of mRNAs are polyadenylated by the more distantly related poly $(\mathrm{A})$ polymerase called Star-PAP/PAPD2 in response to specific signal transduction (Gonzales et al. 2008). Strikingly, $80 \%$ knockdown of PAP $\alpha$ only has a small effect on the $\operatorname{poly}(\mathrm{A})$ population in the cell, but still causes a significant reduction in the induction of CXCL1, CCL2, and IL8 mRNA, suggesting that PAP $\alpha$ is perhaps more important for the expression of inflammatory genes than for general gene expression (Fig. 8). Possibly, PAP $\alpha$ has a higher propensity to use cordycepin triphosphate than other poly(A) polymerases, leading to preferential shortening of transcripts polyadenylated by this enzyme. Such a mechanism could explain the specific effect of cordycepin on the inflammatory genes.

Cordycepin reduces poly(A) tail lengths in treated cells, but does not lead to significant accumulation of cordycepinterminated mRNAs (Fig. 1). In addition, termination and cleavage defects are observed on three genes in cordycepintreated cells (Fig. 6), similar to effects previously observed in vitro (Ryner and Manley 1987) and in yeast (Holbein et al. 2009). It is therefore likely that the effect of cordycepin on gene expression is at least in part mediated by a stabilization of an intermediate $3^{\prime}$ processing complex (Zarkower and Wickens 1987), leading either to a depletion of factors or to a block in the normal exchange of factors on the $3^{\prime}$ end of the pre-mRNA. The cordycepin-arrested cleavage complex has been shown to contain factors involved in other aspects of the regulation of gene expression, including transcriptional regulators and mRNA export factors (Shi et al. 2009). Mutations in chromatin remodeling factors including SWI/SNF components and subunits of the SAGA complex have indeed been shown to increase cordycepin sensitivity in yeast, indicating that gene-specific effects of cordycepin may be linked to differences in chromatin structure (Holbein et al. 2009). In addition, one of the NFкB subunits, c-Rel, has been 
reported to interact with PAP $\alpha$ (Bouwmeester et al. 2004). Possibly, the rapid transcriptional induction of inflammatory genes requires increased loading of poly $(\mathrm{A})$ polymerase to enable the $3^{\prime}$ processing and mRNA export machinery to keep up with RNA synthesis, leading to the observed sensitivity to the inhibition of polyadenylation.

The current anti-inflammatory drugs fall predominantly into just two categories, limiting therapeutic choice. The nonsteroid anti-inflammatory drugs (NSAIDs) inhibit cyclooxygenases including PTGS2 (COX2), an enzyme produced during the inflammatory response, and thereby reduce the effects of inflammation. In contrast, anti-inflammatory steroids act at the start of the inflammatory response. They reduce the transcriptional activation of inflammatory genes, thereby directly reducing inflammation. Both drug classes can have serious side effects and are ineffective for some patients and conditions (Barnes and Adcock 2009; Rainsford 2009; Chou et al. 2010; Poetker and Reh 2010). Therefore, anti-inflammatory drugs acting by an alternative mechanism could potentially benefit a variety of patients. Gene-specific differences in transcription termination and the efficiency of $3^{\prime}$ processing have not received much attention as potential regulators of gene expression or as targets for therapeutic intervention. It was demonstrated only recently that these processes can have major effects on gene expression levels (West and Proudfoot 2009). The data presented here indicate that inflammatory genes have different $3^{\prime}$ processing requirements than other genes, and that these differences can be targeted by small molecule inhibitors, opening up the possibility of anti-inflammatory drugs working by a completely novel mechanism.

\section{MATERIALS AND METHODS}

\section{Reagents}

Cordycepin, nitrobenzylthioinosine (NBTI), actinomycin D (ActD), and iodotubericidin (ITU) were purchased from Sigma and dissolved in DMSO at a 1000 -fold concentrated stock to obtain the indicated final concentrations. 8-Chloroadenosine and 8 -aminoadenosine were purchase from Carbosynth. Thiouridine was obtained from Sigma.

\section{Tissue culture}

NIH3T3 cells were newly obtained from the ECACC and cultured in DMEM with $10 \%$ calf serum with $4.5 \mathrm{~g} / \mathrm{L}$ of glucose. HeLa and A549 lung epithelial carcinoma cells were cultured in DMEM with $10 \%$ fetal bovine serum with $4.5 \mathrm{~g} / \mathrm{L}$ of glucose and $4 \mathrm{mM}$ glutamine. Primary cultures from human airway smooth muscle cells (ASM) were prepared from explants as described previously (Pang and Knox 1997). The cells were cultured in DMEM supplemented with $10 \%$ fetal bovine serum, $100 \mathrm{U} / \mathrm{mL}$ penicillin, $0.1 \mathrm{mg} / \mathrm{mL}$ streptomycin, $0.025 \mathrm{mg} / \mathrm{mL}$ amphotericin $\mathrm{B}$, and $4 \mathrm{mM} \mathrm{L}$-glutamine. All experiments were performed on a single batch of cells at passage 6 at 100\% confluency. Before treatment with cytokines, cells were serum starved for $24 \mathrm{~h}$. TNF treatment was with $10 \mathrm{ng} / \mathrm{mL}$, interleukin $1 \beta$ treatment at $2 \mathrm{ng} / \mathrm{mL}$, for the indicated times. Cell viability was determined with the MTT assay by labeling for $8 \mathrm{~h}$ as described previously (Clarke et al. 2004).

\section{RNA isolation, end labeling, thiouridine labeling, and ${ }^{35} \mathrm{~S}$ labeling}

Total RNA was isolated using the NucleoSpin RNA II isolation kit (Macherey-Nagel) or Tri Reagent (Sigma). If required, nuclear and cytoplasmic fractions were separated using the CelLytic NuCLEAR Extraction Kit (Sigma) or as described previously (Felton-Edkins et al. 2006). 3'-End labeling using pCp and RNA ligase was performed as described (Minvielle-Sebastia et al. 1991). For oligo dT purification of poly(A) RNA we used the PolyAttract kit (Promega). 5'-End labeling was performed with T4 polynucleotide kinase and $\left[\gamma-\mathrm{P}^{32}\right]$ ATP. For thiouridine labeling, cells were incubated with $500 \mu \mathrm{M}$ thiouridine for the indicated times. RNA was then isolated with Tri Reagent (Sigma) and the labeled RNA purified by coupling with biotin, capture on streptavidin paramagnetic particles (Promega), and elution with $\beta$ mercaptoethanol (Dolken et al. 2008). The eluates were precipitated with RNase free glycogen (Roche) as a carrier and dissolved in water. For chromatin-associated, nucleoplasmic, and cytoplasmic RNA isolation, nuclei were isolated as described previously (FeltonEdkins et al. 2006), followed by extraction of RNA from the nuclei as described (Wuarin and Schibler 1994; Dye et al. 2006). The cytoplasmic and nucleoplasmic extracts were precipitated with 1 volume of isopropanol with glycogen as a carrier, and centrifuged. The pellets (including the chromatin pellet) were dissolved in the lysis buffer of a Macherey-Nagel RNA isolation kit. An additional DNAse treatment was performed on the isolated RNA from the nucleoplasmic and chromatin-associated fractions. ${ }^{35} \mathrm{~S}$-labeling of proteins for the determination of protein synthesis rates was performed by labeling for $20 \mathrm{~min}$ as described (Wong et al. 2010).

\section{Quantitative PCR}

For RT-qPCR, reverse transcription was performed using M-MLV Reverse transcriptase (Promega) or Superscript III (Invitrogen) and random hexamers. Quantitative PCR was performed in triplicate on each sample using SYBR Premix Ex Taq TaKaRa (Lonza) or GoTaq qPCR Master Mix (Promega). RNA levels were expressed relative to GAPDH mRNA levels, except for Figure 4, A and $\mathrm{B}$, where ribosomal RNA was used. Cordycepin did not affect GAPDH mRNA levels in total RNA or ribosomal RNA precursor levels in nuclear RNA (data not shown). Melting curves were checked and control reactions lacking reverse transcription were performed. For primer sequences see Supplemental Table 1.

\section{Western blotting and ELISA}

Proteins were extracted by scraping the cells in RIPA buffer (50 mM Tris- $\mathrm{HCl}$ at $\mathrm{pH} 7.4,150 \mathrm{mM} \mathrm{NaCl}, 1 \mathrm{mM}$ EDTA, $1 \%$ NP40, 0.25\% sodium deoxycholate, $1 \mathrm{mM} \mathrm{PMSF,} 1 \mathrm{mM} \mathrm{Na}_{3} \mathrm{VO}_{4}$, $0.5 \mathrm{mM}$ DTT, 1x protease inhibitor cocktail [Sigma]), followed by centrifugation for $10 \mathrm{~min}$ at $21,000 \mathrm{~g}$ at $4^{\circ} \mathrm{C}$. The soluble protein extract was quantified with the Pierce BCA Protein Assay Kit (Thermo Scientific). Proteins were detected by Western Blotting using the following antibodies: COX-2 monoclonal antibody clone CX229 (Cayman Chemical), IкB- $\alpha$ (Cell Signaling), NFкB 
p65 C-20, lamin A/C 636, GAPDH 0411 (Santa Cruz Biotechnology), PAPOLA (Novus Biologicals). To determine cytokine production, medium was collected and analyzed using DuoSet ELISA Development Systems for human IL8, CCL2, and CCL11 (R\&D Systems).

\section{Chromatin immunoprecipitation}

Chromatin immunoprecipitation (ChIP) was performed using the ChIP-IT Express kit (Active Motif). A total of $50 \mu \mathrm{L}$ of chromatin and $4 \mu \mathrm{g}$ of the following antibodies were used for the immunoprecipitations: NFкB p65 C-20, PolII H-224 (Santa Cruz Biotechnology), and normal rabbit IgG (R\&D Systems).

\section{Reporter gene assays}

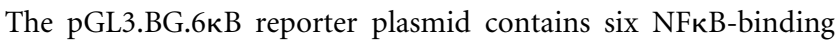
sites upstream of a basal promoter that drives transcription of the firefly luciferase coding mRNA and terminates in the SV40 late poly(A) signal (Schwarzer et al. 1998). Precise fusions of the SV40 sequences up to the poly(A) signal and $1 \mathrm{~kb}$ of terminator sequences from the indicated genes were achieved by splice PCR (Muddashetty et al. 2002) using the cloning primers indicated in Supplemental Table 1. The fused sequences were inserted in the $\mathrm{XbaI}$ and BamH1 sites, replacing the SV40 termination sequences of the original plasmid and checked by sequencing. These firefly luciferase reporter vectors were cotransfected into A549 cells using Fugene 6 (Roche) in combination with Ubi-Renilla (Felton-Edkins et al. 2006) to correct for transfection efficiency. After $48 \mathrm{~h}$, the cells were treated with TNF and cordycepin as indicated. The renilla and firefly reporter activities were measured using the Dual Luciferase Assay (Promega).

\section{siRNA knockdown of PAPOLA}

Poly(A) polymerase $\alpha$ (PAPOLA) levels were knocked down in ASM cells or A549 lung carcinoma cells using the Smartpool siRNA (5 nM) against PAPOLA (Dharmacon) and INTERFERin (Polyplus). Cells were transfected in serum containing medium according to the manufacturer's instructions. The day after, the medium was replaced with serum-free medium and the transfection was repeated. Twenty-four hours later, the cells were treated with TNF for $1 \mathrm{~h}$ as described.

\section{SUPPLEMENTAL MATERIAL}

Supplemental material is available for this article.

\section{ACKNOWLEDGMENTS}

This work was supported by the Biotechnology and Biological Sciences Research Council (grant no. BB/G001847/1) and the Wellcome Trust (grant no. WT078227MA). Nicholas Proudfoot (Oxford), Sebastiaan Winkler, and David Heery (Nottingham) are thanked for critical reading of different versions of this manuscript. M.S. and S.T. were Erasmus exchange students from the University of Rennes 1 during the spring of 2010.

Author contributions: A. Kondrashov, H.A.M., and C.H.deM. developed the concepts and designed the experiments. A. Kondrashov, H.A.M., and A.B-B. performed the majority of the experiments.
C.H.deM., H.P., A. Khurshid, S.T., and M.S. performed minor experiments. A.J.K., L.P., and C.H.deM. supervised the experimental work. C.H.deM. wrote the paper.

Received January 12, 2012; accepted September 14, 2012.

\section{REFERENCES}

Åstrom J, ̊̊strom A, Virtanen A. 1991. In vitro deadenylation of mammalian mRNA by a HeLa cell $3^{\prime}$ exonuclease. EMBO $J \mathbf{1 0}$ : 3067-3071.

Banerjee A, Sammarco MC, Ditch S, Wang J, Grabczyk E. 2009. A novel tandem reporter quantifies RNA polymerase II termination in mammalian cells. PLoS ONE 4: e6193. doi: 10.1371/journal.pone.0006193.

Barnes PJ. 2010. New therapies for asthma: Is there any progress? Trends Pharmacol Sci 31: 335-343.

Barnes PJ, Adcock IM. 2009. Glucocorticoid resistance in inflammatory diseases. Lancet 373: 1905-1917.

Beg AA, Baltimore D. 1996. An essential role for NF- $\kappa$ B in preventing TNF- $\alpha$-induced cell death. Science 274: 782-784.

Bontemps F, Van den Berghe G, Hers HG. 1983. Evidence for a substrate cycle between AMP and adenosine in isolated hepatocytes. Proc Natl Acad Sci 80: 2829-2833.

Bouwmeester T, Bauch A, Ruffner H, Angrand PO, Bergamini G, Croughton K, Cruciat C, Eberhard D, Gagneur J, Ghidelli S, et al. 2004. A physical and functional map of the human TNF- $\alpha / N F-\kappa$ B signal transduction pathway. Nat Cell Biol 6: 97-105.

Chen LS, Du-Cuny L, Vethantham V, Hawke DH, Manley JL, Zhang S, Gandhi V. 2009. Chain termination and inhibition of mammalian poly(A) polymerase by modified ATP analogues. Biochem Pharmacol 79: 669-677.

Chen Y, Chen YC, Lin YT, Huang SH, Wang SM. 2010. Cordycepin induces apoptosis of CGTH W-2 thyroid carcinoma cells through the calcium-calpain-caspase 7-PARP pathway. J Agric Food Chem 58: 11645-11652.

Cheng Z, He W, Zhou X, Lv Q, Xu X, Yang S, Zhao C, Guo L. 2011. Cordycepin protects against cerebral ischemia/reperfusion injury in vivo and in vitro. Eur J Pharmacol 664: 20-28.

Chipumuro E, Henriksen MA. 2011. The ubiquitin hydrolase USP22 contributes to $3^{\prime}$-end processing of JAK-STAT-inducible genes. FASEB J 26: 842-854.

Chou R, Helfand M, Peterson K, Dana T, Roberts C, Chakraborti AK, Garg SK, Kumar R, Motiwala HF, Jadhavar PS. 2010. Progress in COX-2 inhibitors: A journey so far. Curr Med Chem 17: 15631593.

Clarke DL, Belvisi MG, Catley MC, Yacoub MH, Newton R, Giembycz MA. 2004. Identification in human airways smooth muscle cells of the prostanoid receptor and signalling pathway through which PGE2 inhibits the release of GM-CSF. Br J Pharmacol 141: 11411150.

Di Giammartino DC, Nishida K, Manley JL. 2011. Mechanisms and consequences of alternative polyadenylation. Mol Cell 43: 853866.

Dolken L, Ruzsics Z, Radle B, Friedel CC, Zimmer R, Mages J, Hoffmann R, Dickinson P, Forster T, Ghazal P, et al. 2008. Highresolution gene expression profiling for simultaneous kinetic parameter analysis of RNA synthesis and decay. RNA 14: 19591972.

Dye MJ, Gromak N, Proudfoot NJ. 2006. Exon tethering in transcription by RNA polymerase II. Mol Cell 21: 849-859.

Felton-Edkins ZA, Kondrashov A, Karali D, Fairley JA, Dawson CW, Arrand JR, Young LS, White RJ. 2006. Epstein-Barr virus induces cellular transcription factors to allow active expression of EBER genes by RNA polymerase III. J Biol Chem 281: 33871-33880.

Gonzales ML, Mellman DL, Anderson RA. 2008. CKI $\alpha$ is associated with and phosphorylates star-PAP and is also required for 
expression of select star-PAP target messenger RNAs. J Biol Chem 283: 12665-12673.

Hao S, Baltimore D. 2009. The stability of mRNA influences the temporal order of the induction of genes encoding inflammatory molecules. Nat Immunol 10: 281-288.

Hirose Y, Manley JL. 1998. RNA polymerase II is an essential mRNA polyadenylation factor. Nature 395: 93-96.

Hoffmann A, Leung TH, Baltimore D. 2003. Genetic analysis of NF$\mathrm{\kappa B} /$ Rel transcription factors defines functional specificities. $E M B O$ J 22: 5530-5539.

Holbein S, Wengi A, Decourty L, Freimoser FM, Jacquier A, Dichtl B. 2009. Cordycepin interferes with $3^{\prime}$ end formation in yeast independently of its potential to terminate RNA chain elongation. $R N A$ 15: $837-849$.

Houseley J, Tollervey D. 2008. The nuclear RNA surveillance machinery: The link between ncRNAs and genome structure in budding yeast? Biochim Biophys Acta 1779: 239-246.

Hummasti S, Hotamisligil GS. 2010. Endoplasmic reticulum stress and inflammation in obesity and diabetes. Circ Res 107: 579-591.

Karin M. 2006. NF- $\mathrm{BB}$ and cancer: Mechanisms and targets. Mol Carcinog 45: 355-361.

Kashiwabara SI, Nakanishi T, Kimura M, Baba T. 2008. Non-canonical poly(A) polymerase in mammalian gametogenesis. Biochim Biophys Acta 1779: 230-238.

Katoh T, Sakaguchi Y, Miyauchi K, Suzuki T, Kashiwabara S, Baba T, Suzuki T. 2009. Selective stabilization of mammalian microRNAs by $3^{\prime}$ adenylation mediated by the cytoplasmic poly(A) polymerase GLD-2. Genes Dev 23: 433-438.

Kim H, Naura AS, Errami Y, Ju J, Boulares AH. 2011. Cordycepin blocks lung injury-associated inflammation and promotes BRCA1deficient breast cancer cell killing by effectively inhibiting PARP. Mol Med 17: 893-900.

Kitamura M, Kato H, Saito Y, Nakajima S, Takahashi S, Johno H, Gu L, Katoh R. 2011. Aberrant, differential and bidirectional regulation of the unfolded protein response towards cell survival by $3^{\prime}$ deoxyadenosine. Cell Death Differ 18: 1876-1888.

Kredich NM. 1980. Inhibition of nucleic acid methylation by cordycepin. In vivo synthesis of S-3'-deoxyadenosylmethionine by WI-L2 human lymphoblasts. J Biol Chem 255: 7380-7385.

Lee SJ, Kim SK, Kim WJ, Moon SK. 2009. Cordycepin causes p21WAF1-mediated G2/M cell-cycle arrest by regulating c-Jun N-terminal kinase activation in human bladder cancer cells. Arch Biochem Biophys 490: 103-109.

Lee SJ, Moon GS, Jung KH, Kim WJ, Moon SK. 2010. c-Jun $\mathrm{N}$-terminal kinase 1 is required for cordycepin-mediated induction of G2/M cell-cycle arrest via p21WAF1 expression in human colon cancer cells. Food Chem Toxicol 48: 277-283.

Luo W, Johnson AW, Bentley DL. 2006. The role of Rat1 in coupling mRNA 3 '-end processing to transcription termination: Implications for a unified allosteric-torpedo model. Genes Dev 20: $954-$ 965.

Mapendano CK, Lykke-Andersen S, Kjems J, Bertrand E, Jensen TH. 2010. Crosstalk between mRNA $3^{\prime}$ end processing and transcription initiation. Mol Cell 40: 410-422.

Martick M, Horan LH, Noller HF, Scott WG. 2008. A discontinuous hammerhead ribozyme embedded in a mammalian messenger RNA. Nature 454: 899-902.

Meaux S, Lavoie M, Gagnon J, Abou ES, Van Hoof A. 2011. Reporter mRNAs cleaved by Rntlp are exported and degraded in the cytoplasm. Nucleic Acids Res 39: 9357-9367.

Milcarek C, Albring M, Langer C, Park KS. 2011. The eleven-nineteen lysine-rich leukemia gene (ELL2) influences the histone $\mathrm{H} 3$ protein modifications accompanying the shift to secretory immunoglobulin heavy chain mRNA production. J Biol Chem 286: 3379533803.

Minvielle-Sebastia L, Winsor B, Bonneaud N, Lacroute F. 1991. Mutations in the yeast RNA14 and RNA15 genes result in an abnormal mRNA decay rate; sequence analysis reveals an RNAbinding domain in the RNA15 protein. Mol Cell Biol 11: 3075-3087.
Moore MJ, Proudfoot NJ. 2009. Pre-mRNA processing reaches back to transcription and ahead to translation. Cell 136: 688-700.

Muddashetty R, Khanam T, Kondrashov A, Bundman M, Iacoangeli A, Kremerskothen J, Duning K, Barnekow A, Huttenhofer A, Tiedge $\mathrm{H}$, et al. 2002. Poly(A)-binding protein is associated with neuronal $\mathrm{BC} 1$ and $\mathrm{BC} 200$ ribonucleoprotein particles. J Mol Biol 321: $433-445$.

Mukundan B, Ansari A. 2011. Novel role for mediator complex subunit Srb5/Med18 in termination of transcription. J Biol Chem 286: 37053-37057.

Nagaike T, Logan C, Hotta I, Rozenblatt-Rosen O, Meyerson M, Manley JL. 2011. Transcriptional activators enhance polyadenylation of mRNA precursors. Mol Cell 41: 409-418.

Nakamura K, Konoha K, Yoshikawa N, Yamaguchi Y, Kagota S, Shinozuka K, Kunitomo M. 2005. Effect of cordycepin (3'deoxyadenosine) on hematogenic lung metastatic model mice. In Vivo 19: 137-141.

Nakamura K, Yoshikawa N, Yamaguchi Y, Kagota S, Shinozuka K, Kunitomo M. 2006. Antitumor effect of cordycepin (3'-deoxyadenosine) on mouse melanoma and lung carcinoma cells involves adenosine A3 receptor stimulation. Anticancer Res 26: 43-47.

Newby AC, Holmquist CA, Illingworth J, Pearson JD. 1983. The control of adenosine concentration in polymorphonuclear leucocytes, cultured heart cells and isolated perfused heart from the rat. Biochem J 214: 317-323.

Noh EM, Kim JS, Hur H, Park BH, Song EK, Han MK, Kwon KB, Yoo WH, Shim IK, Lee SJ, et al. 2009. Cordycepin inhibits IL-1 $\beta$ induced MMP-1 and MMP-3 expression in rheumatoid arthritis synovial fibroblasts. Rheumatology (Oxford) 48: 45-48.

Pang L, Knox AJ. 1997. Effect of interleukin-1 $\beta$, tumour necrosis factor- $\alpha$ and interferon- $\gamma$ on the induction of cyclo-oxygenase- 2 in cultured human airway smooth muscle cells. Br J Pharmacol 121: $579-587$.

Parkinson FE, Geiger JD. 1996. Effects of iodotubercidin on adenosine kinase activity and nucleoside transport in DDT1 MF-2 smooth muscle cells. J Pharmacol Exp Ther 277: 1397-1401.

Penman S, Rosbash M, Penman M. 1970. Messenger and heterogeneous nuclear RNA in HeLa cells: Differential inhibition by cordycepin. Proc Natl Acad Sci 67: 1878-1885.

Poetker DM, Reh DD. 2010. A comprehensive review of the adverse effects of systemic corticosteroids. Otolaryngol Clin North Am 43: $753-768$.

Proudfoot NJ. 2011. Ending the message: poly(A) signals then and now. Genes Dev 25: 1770-1782.

Puntmann VO, Taylor PC, Mayr M. 2010. Coupling vascular and myocardial inflammatory injury into a common phenotype of cardiovascular dysfunction: Systemic inflammation and aging - A mini-review. Gerontology 57: 295-303.

Radford HE, Meijer HA, De Moor CH. 2008. Translational control by cytoplasmic polyadenylation in Xenopus oocytes. Biochim Biophys Acta 1779: 217-229.

Rainsford KD. 2009. Ibuprofen: Pharmacology, efficacy and safety. Inflammopharmacology 17: 275-342.

Rammelt C, Bilen B, Zavolan M, Keller W. 2011. PAPD5, a noncanonical poly(A) polymerase with an unusual RNA-binding motif. RNA 17: 1737-1746.

Richard P, Manley JL. 2009. Transcription termination by nuclear RNA polymerases. Genes Dev 23: 1247-1269.

Rose KM, Bell LE, Jacob ST. 1977. Specific inhibition of chromatinassociated poly(A) synthesis in vitro by cordycepin $5^{\prime}$-triphosphate. Nature 267: 178-180.

Rozenblatt-Rosen O, Nagaike T, Francis JM, Kaneko S, Glatt KA, Hughes CM, LaFramboise T, Manley JL, Meyerson M. 2009. The tumor suppressor Cdc73 functionally associates with CPSF and CstF 3' mRNA processing factors. Proc Natl Acad Sci 106: 755760.

Ryner LC, Manley JL. 1987. Requirements for accurate and efficient mRNA 3' end cleavage and polyadenylation of a simian virus 40 early pre-RNA in vitro. Mol Cell Biol 7: 495-503. 
Sagawa F, Ibrahim H, Morrison AL, Wilusz CJ, Wilusz J. 2011. Nucleophosmin deposition during mRNA $3^{\prime}$ end processing influences poly(A) tail length. EMBO J 30: 3994-4005.

Schwarzer N, Nost R, Seybold J, Parida SK, Fuhrmann O, Krull M, Schmidt R, Newton R, Hippenstiel S, Domann E, et al. 1998. Two distinct phospholipases C of Listeria monocytogenes induce ceramide generation, nuclear factor- $\kappa$ B activation, and E-selectin expression in human endothelial cells. J Immunol 161: 3010-3018.

SenGupta DJ, Lum PY, Lai Y, Shubochkina E, Bakken AH, Schneider G, Unadkat JD. 2002. A single glycine mutation in the equilibrative nucleoside transporter gene, hENT1, alters nucleoside transport activity and sensitivity to nitrobenzylthioinosine. Biochemistry 41 : 1512-1519.

Shcherbik N, Wang M, Lapik YR, Srivastava L, Pestov DG. 2010. Polyadenylation and degradation of incomplete RNA polymerase I transcripts in mammalian cells. EMBO Rep 11: 106-111.

Shi Y, Di Giammartino DC, Taylor D, Sarkeshik A, Rice WJ, Yates JR III, Frank J, Manley JL. 2009. Molecular architecture of the human pre-mRNA 3' processing complex. Mol Cell 33: 365-376.

Tian B, Nowak DE, Jamaluddin M, Wang S, Brasier AR. 2005. Identification of direct genomic targets downstream of the nuclear factor- $\mathrm{\kappa} \mathrm{B}$ transcription factor mediating tumor necrosis factor signaling. J Biol Chem 280: 17435-17448.

Topalian SL, Kaneko S, Gonzales MI, Bond GL, Ward Y, Manley JL. 2001. Identification and functional characterization of neopoly(A) polymerase, an RNA processing enzyme overexpressed in human tumors. Mol Cell Biol 21: 5614-5623.

Wahle E, Rüegsegger U. 1999. 3' end processing of pre-mRNA in eukaryotes. FEMS Microbiol Rev 23: 277-295.

Waldholm J, Wang Z, Brodin D, Tyagi A, Yu S, Theopold U, Farrants AK, Visa N. 2011. SWI/SNF regulates the alternative processing of a specific subset of pre-mRNAs in Drosophila melanogaster. BMC Mol Biol 12: 46. doi: 10.1186/1471-2199-12-46.
Wang Y, Fairley JA, Roberts SG. 2010. Phosphorylation of TFIIB links transcription initiation and termination. Curr Biol 20: 548-553.

Ward JL, Sherali A, Mo ZP, Tse CM. 2000. Kinetic and pharmacological properties of cloned human equilibrative nucleoside transporters, ENT1 and ENT2, stably expressed in nucleoside transporterdeficient PK15 cells. Ent2 exhibits a low affinity for guanosine and cytidine but a high affinity for inosine. J Biol Chem 275: 8375-8381.

West S, Proudfoot NJ. 2009. Transcriptional termination enhances protein expression in human cells. Mol Cell 33: 354-364.

West S, Proudfoot NJ, Dye MJ. 2008. Molecular dissection of mammalian RNA polymerase II transcriptional termination. $\mathrm{Mol}$ Cell 29: 600-610.

Winkler D. 2010. Cordyceps sinensis: A precious parasitic fungus infecting Tibet. Field Mycology 11: 60-67.

Wong YY, Moon A, Duffin R, Barthet-Barateig A, Meijer HA, Clemens MJ, De Moor CH. 2010. Cordycepin inhibits protein synthesis and cell adhesion through effects on signal transduction. J Biol Chem 285: 2610-2621.

Wuarin J, Schibler U. 1994. Physical isolation of nascent RNA chains transcribed by RNA polymerase II: Evidence for cotranscriptional splicing. Mol Cell Biol 14: 7219-7225.

Yen L, Svendsen J, Lee JS, Gray JT, Magnier M, Baba T, D’Amato RJ, Mulligan RC. 2004. Exogenous control of mammalian gene expression through modulation of RNA self-cleavage. Nature 431: $471-476$.

Zarkower D, Wickens M. 1987. Specific pre-cleavage and postcleavage complexes involved in the formation of SV40 late mRNA $3^{\prime}$ termini in vitro. EMBO J 6: 4185-4192.

Zeevi M, Nevins JR, Darnell JE Jr. 1982. Newly formed mRNA lacking polyadenylic acid enters the cytoplasm and the polyribosomes but has a shorter half-life in the absence of polyadenylic acid. Mol Cell Biol 2: 517-525.

Zhang X, Virtanen A, Kleiman FE. 2010. To polyadenylate or to deadenylate: That is the question. Cell Cycle 9: 4437-4449. 

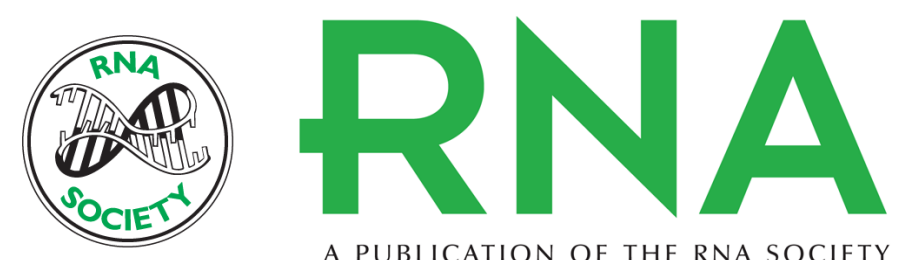

A PUBLICATION OF THE RNA SOCIETY

\section{Inhibition of polyadenylation reduces inflammatory gene induction}

Alexander Kondrashov, Hedda A. Meijer, Adeline Barthet-Barateig, et al.

RNA 2012 18: 2236-2250 originally published online November 1, 2012

Access the most recent version at doi:10.1261/rna.032391.112

Supplemental

Material

References This article cites 79 articles, 31 of which can be accessed free at: http://rnajournal.cshlp.org/content/18/12/2236.full.html\#ref-list-1

Open Access Freely available online through the RNA Open Access option.

License Freely available online through the RNA Open Access option.

Email Alerting Receive free email alerts when new articles cite this article - sign up in the box at the Service top right corner of the article or click here. 